\title{
Acute Exposure to a Precursor of Advanced Glycation End Products Induces a Dual Effect on the Rat Pancreatic Islet Function
}

\author{
Ghada Elmhiri, ${ }^{1}$ Luiz Felipe Barella, ${ }^{2}$ Didier Vieau, ${ }^{3}$ Sylvaine Camous, ${ }^{4}$ \\ Paulo C. F. Mathias, ${ }^{2}$ and Latifa Abdennebi-Najar' \\ ${ }^{1}$ Institut Polytechnique LaSalle Beauvais, EGEAL-UP 2012.10.101., 19 rue Pierre Waguet, 60026 Beauvais Cedex, France \\ ${ }^{2}$ Laboratory of Secretion Cell Biology, Department of Biotechnology, Genetics and Cell Biology, State University of Maringá, \\ 87020-900 Maringá, PR, Brazil \\ ${ }^{3}$ Environnement Périnatal et Croissance (EA4489), Equipe Dénutritions Maternelles Périnatales, \\ SN4, Université de Lille 1, 59655 Villeneuve d'Ascq, France \\ ${ }^{4}$ INRA, UMR1198, Biologie du Développement et Reproduction, 78352 Jouy en Josas, France
}

Correspondence should be addressed to Latifa Abdennebi-Najar; latifa.najar@lasalle-beauvais.fr

Received 14 July 2014; Accepted 20 October 2014; Published 17 November 2014

Academic Editor: Dario Iafusco

Copyright (C) 2014 Ghada Elmhiri et al. This is an open access article distributed under the Creative Commons Attribution License, which permits unrestricted use, distribution, and reproduction in any medium, provided the original work is properly cited.

\begin{abstract}
Aim. Chronic diseases are the leading cause of death worldwide. Advanced glycation end products, known as AGEs, are a major risk factor for diabetes onset and maintenance. Methylglyoxal (MG), a highly reactive metabolite of glucose, is a precursor for the generation of endogenous AGEs. Methods. In this current study we incubated in vitro pancreatic islets from adult rats in absence or presence of MG $(10 \mu \mathrm{mol} / \mathrm{l})$ with different concentrations of glucose and different metabolic components (acetylcholine, epinephrine, potassium, forskolin, and leucine). Results. Different effects of MG on insulin secretion were evidenced. In basal glucose stimulation $(5.6 \mathrm{mM}), \mathrm{MG}$ induced a significant $(P<0.05)$ increase of insulin secretion. By contrast, in higher glucose concentrations $(8.3 \mathrm{mM}$ and $16.7 \mathrm{mM}), \mathrm{MG}$ significantly inhibited insulin secretion $(P<0.05)$. In the presence of potassium, forskolin, and epinephrine, MG enhanced insulin secretion $(P<0.05)$, while when it was incubated with acetylcholine and leucine, MG resulted in a decrease of insulin secretion $(P<0.05)$. Conclusion. We suggest that MG modulates the secretion activity of betacell depending on its level of stimulation by other metabolic factors. These results provide insights on a dual acute effect of MG on the pancreatic cells.
\end{abstract}

\section{Introduction}

Glycemia and diabetes are rising globally accounting 347 million people worldwide. The study of type 2 diabetes (T2D) has been stimulated due to its growing pandemic and intricate physiopathology, in search of better ways of prevention and treatment of the T2D and its associated complications [1]. Among the several studies to explain the different causative factors and their roles in the onset and maintenance of the T2D and pancreatic islet dysfunctions, the formation of the advanced glycation end products (AGEs) has gained significant importance [2]. For example, it has been reported that patients with diabetes present increased serum concentrations of AGEs compared with nondiabetic patients [3].

AGEs are formed and accumulated by endogenous and exogenous ways. Among the mechanisms, these molecules can increase their intracellular concentrations through the autooxidation of glucose resulting in glyoxal [4] that can undergo a final fragmentation producing the methylglyoxal [5]. Glyoxal and methylglyoxal interact with amino groups of intracellular and extracellular proteins to produce the AGEs. In addition to the prevailing formation of AGEs under physiological conditions and their increase under conditions of hyperglycemia and oxidative stress [6], these products 
are also introduced in the organism by means of exogenous sources, such as tobacco and diet. The diet is considered the main exogenous source of AGEs and is associated with the development of several pathologies such as diabetes [7]. Food preparation methods using high temperatures (frying, roasting, and grilling) potentialize the production of AGEs present in the diets; moreover, high-fat foods are the main contributors to the formation of AGEs in the diets [8]. Thus, both the endogenous and exogenous AGEs influence the installation and progression of pathologies like T2D.

The pancreatic islet insulin secretion is highly regulated by glucose and secretagogues. Glucose is responsible for the triggering of insulin release while the secretagogues may amplify or inhibit the release depending on their interactions. The triggering and amplifying pathways were widely reviewed in the literature [9-12]. Recent studies have shown that AGEs long-term exposure may impair the beta-cell function by inducing apoptosis or decreasing the insulin secretion $[13,14]$. However, the specific sites of interactions of the AGEs on the different pathways of insulin secretion remain to be elucidated [15].

Our current study highlights the acute effect of incubation of a precursor of AGEs, methylglyoxal (MG), on the insulin secretion triggered by glucose and modulated by different secretagogues. Our findings revealed that MG exerts a dual role on the insulin secretion depending on both glucose concentration and the type of secretagogue.

\section{Materials and Methods}

2.1. Animals. The experiments were conducted in accordance with the European Communities Council Directive of 1986 (86/609/EEC) and approved by the French Departmental Direction of Veterinary Services Committee.

Ten adult Wistar rats were purchased from Harlan Laboratories (Gannat, France) and housed two per cage. The animal facility rooms were maintained on a dark/light schedule $(12 \mathrm{~h} / 12 \mathrm{~h}$, light on at $08 \mathrm{~h})$ and controlled temperature $\left(22 \pm 2^{\circ} \mathrm{C}\right)$. Animals were maintained with free access to food (regular rat chow diet) and tap water. After a week of acclimation, the rats weighing around 350 grams were used to the subsequent experiments.

2.2. Isolation of the Pancreatic Islets. Pancreatic islets were isolated by the collagenase method as previously described [16], with adaptations. The animals were decapitated and the abdominal wall was cut open. Following, $8 \mathrm{~mL}$ of Hanks buffered saline solution (HBSS; (mM): $\mathrm{NaCl}, 136.9$; $\mathrm{KCl}$, 5.4; $\mathrm{MgSO}_{4} 7 \mathrm{H}_{2} \mathrm{O}, 0.81 ; \mathrm{Na}_{2} \mathrm{HPO}_{4}, 0.34 ; \mathrm{KH}_{2} \mathrm{PO}_{4}$, 0.44; $\mathrm{CaCl}_{2} 2 \mathrm{H}_{2} \mathrm{O}, 1.26 ; \mathrm{NaHCO}_{3}$, 4.16; glucose, 0.06; BSA, $15)$; and $\left(\left(\mathrm{v} / \mathrm{v} ; 95 \% \mathrm{O}_{2}+5 \% \mathrm{CO}_{2}\right.\right.$, mixed $) / 10 \mathrm{~min}, \mathrm{pH}$ 7.4) containing ((w/v) $0.1 \%$ collagenase type XI, 5\% BSA and $0.6 \% \mathrm{~N}$-(2-hydroxyethylpiperazine)- $\mathrm{N}^{\prime}$-(2-ethanesulfonic acid; HEPES); Sigma-Aldrich) was injected into the rats' common bile duct. The inflated pancreas with collagenase was incubated at $37^{\circ} \mathrm{C}$. The pancreas was washed with HBSS and the islets were hand-picked with the aid of a stereomicroscope.
2.3. Functional Study of the Insulin Secretion. To adapt the pancreatic islets, they were preincubated for $60 \mathrm{~min}$ in $1 \mathrm{~mL}$ of normal Krebs-Ringer solution ((mM): $\mathrm{NaCl}, 115 ; \mathrm{NaHCO}_{3}$, 24; $\mathrm{KCl}, 1.6 ; \mathrm{MgCl}_{6} \mathrm{H}_{2} \mathrm{O}, 1 ; \mathrm{CaCl}_{2} 2 \mathrm{H}_{2} \mathrm{O}, 1 ; \mathrm{BSA}, 15 ; \mathrm{pH}$ 7.4) containing $5.6 \mathrm{mmol} / \mathrm{L}$ glucose. This solution was gassed with (v/v) $95 \% \mathrm{O}_{2} \mathrm{C}^{2} \% \mathrm{CO}_{2}$ (mixed) to maintain $\mathrm{pH}$ 7.4. After the preincubation, groups of 4 islets were incubated with different concentrations of glucose $(5.6,8.3$, and $16.7 \mathrm{mM})$ for an additional $60 \mathrm{~min}$.

To study the different amplifying/inhibiting pathways of insulin secretion, islets were incubated (after the preincubation period) for further $60 \mathrm{~min}$ with $8.3 \mathrm{mM}$ of glucose plus $10 \mu \mathrm{M}$ of acetylcholine in the presence of $10 \mu \mathrm{M}$ of neostigmine to avoid the acetylcholinesterase action; or $16.7 \mathrm{mM}$ of glucose plus $1 \mu \mathrm{M}$ of epinephrine; or $5.6 \mathrm{mM}$ of glucose plus $40 \mathrm{mM}$ of $\mathrm{K}^{+}$; or $8.3 \mathrm{mM}$ of glucose plus $10 \mu \mathrm{M}$ of forskolin; or $5.6 \mathrm{mM}$ of glucose plus $10 \mathrm{mM}$ of leucine. All the incubations were also tested in presence of $10 \mu \mathrm{M}$ of methylglyoxal. Doses were tested before or chosen from the literature to the optimal induction/inhibition of the insulin secretion.

The supernatants from the incubations were collected and stored for posterior insulin measurements using a radioimmunoassay method. All the pharmacological compounds used for the study were purchased from Sigma-Aldrich.

2.4. Statistical Analysis. Data are presented as mean \pm standard error of the mean (S.E.M.). Student's $t$-test was performed using GraphPad Prism version 6.01 for Windows (GraphPad Software, La Jolla, CA, USA).

\section{Results}

To study the effect of MG on insulin release triggered by different concentrations of glucose, cells were incubated with $5.6 \mathrm{mM}, 8.3 \mathrm{mM}$, and $16.7 \mathrm{mM}$ of glucose in presence or absence of MG $(10 \mathrm{mM})$. As shown in Figure 1, at basal glucose concentration, MG induced an increase of $91 \%(P<$ 0.01 ) in the glucose-stimulated insulin secretion (GSIS). However, at 8.3 and $16.7 \mathrm{mM}$ of glucose, the insulin secretion in presence of $M G$ was reduced by $71 \%$ and $42 \%(P<0.01)$, respectively.

Secondly, we studied the effect of MG on islets insulin secretion in presence of different secretagogues. Results shown in Figures 2 and 3 have been expressed as a percentage from the respective basal glucose concentration. In presence of $8.3 \mathrm{mM}$ of glucose, acetylcholine amplified the insulin secretion by $160 \%(P<0.001)$, and the presence of MG decreased the acetylcholine-increased insulin secretion by $27 \%(P<0.001)$, compared with $8.3 \mathrm{mM}$ of glucose. In presence of $16.7 \mathrm{mM}$ of glucose, epinephrine decreased the insulin secretion by $76 \%(P<0.001)$ and the addition of MG resulted in a slight decrease (67\% compared with $16.7 \mathrm{mM}$ of glucose, $P<0.001)$ of the epinephrine-induced inhibition of GSIS. In Figure 3 , the GSIS was increased by $85 \%(P<0.001)$ in presence of $\mathrm{K}^{+}$and $5.6 \mathrm{mM}$ of glucose, and the addition of MG induced by $177 \%(P<0.001)$ the insulin secretion compared with $5.6 \mathrm{mM}$ of glucose. Forskolin induced by $89 \%$ $(P<0.001)$ the insulin secretion in presence of $8.3 \mathrm{mM}$ of 


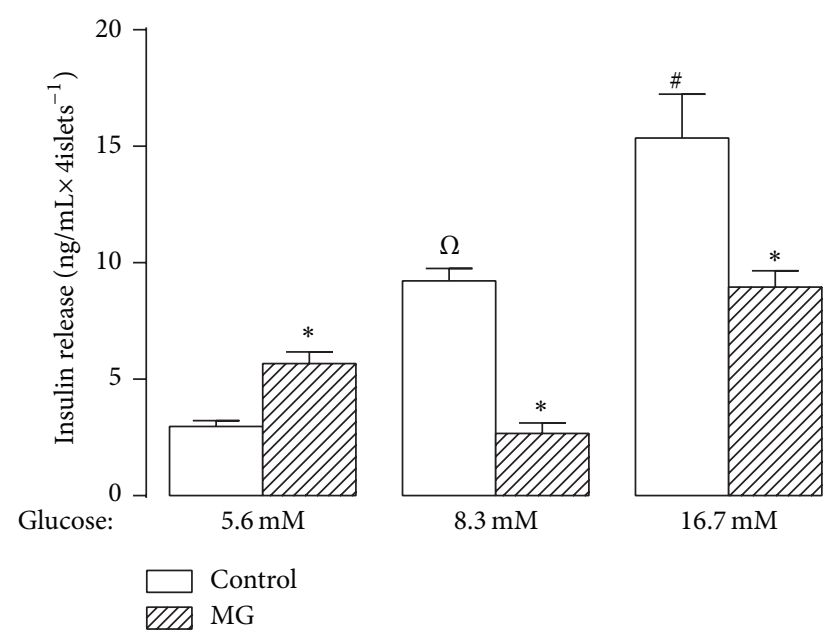

FIGURE 1: Glucose-stimulated insulin secretion (GSIS). Insulinotropic effect of GSIS from isolated pancreatic islets in absence or presence of methylglyoxal. Insulin secretion was stimulated by increasing concentrations of glucose, as indicated below the $x$-axis. Bars represent the mean \pm S.E.M. ${ }^{*} P<0.01$ compared with the respective control group; ${ }^{\Omega} P<0.01$ compared with 5.6 or $16.7 \mathrm{mM}$ of glucose; ${ }^{\#} P<0.01$ compared with 5.6 or $8.3 \mathrm{mM}$ of glucose.

glucose, while the addition of $M G$ resulted in further increase of around 3-fold $(P<0.001)$. Finally, in presence of $5.6 \mathrm{mM}$ of glucose, leucine increased the insulin secretion by $85 \%$ $(P<0.001)$, while in presence of MG this leucine-induced increase of insulin secretion was of $32 \%(P<0.05)$ compared with $5.6 \mathrm{mM}$ of glucose.

\section{Discussion}

Our study provides evidence to support the hypothesis that MG affects the insulin secretion in a dual manner. We have shown that short exposure of a low concentration of MG leads to an imbalance of insulin secretion at both basal and high glucose concentrations as well as in the presence of acetylcholine, epinephrine, potassium, leucine, and forskolin. These results indicate that different pathways are involved in AGEs regulation of insulin secretion and that their mode of action is dependent either on glucose concentration or on the nature of secretagogue applied in the cells. In agreement with a previous study [17], our findings support the idea of a dual effect of AGEs in the regulation of insulin secretion.

Glucose is the main nutrient that initiates the insulin secretion on pancreatic islets. It is internalized by glucose transporters 2 (GLUT2) present in the beta-cell surface. Briefly, within the cells, the glucose is metabolized by oxidative glycolysis, which leads to a rise of the ATP-to-ADP ratio. The increased levels of ATP result in the closure of ATPsensitive potassium channels, which leads to a depolarization of the membrane and subsequent opening of voltagedependent calcium channels and the influx of calcium resulting in the rise of cytoplasmic-free calcium concentration and activation of the exocytotic machinery [9]. The incubation of isolated islets with glucose stimulates the insulin secretion in a concentration-dependent manner [18]. Interestingly, when

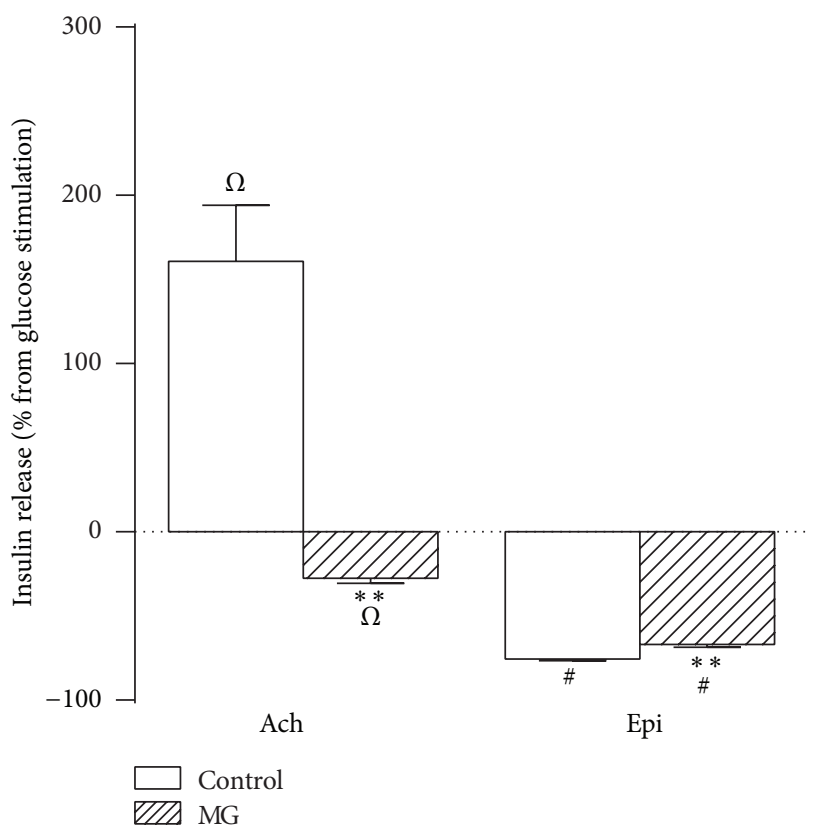

FIGURE 2: Effect of acetylcholine or epinephrine on GSIS. Insulin secretion was stimulated or inhibited by acetylcholine or epinephrine, as indicated below the $x$-axis, in absence or presence of methylglyoxal. Bars represent the mean \pm S.E.M. of the percentage of insulin release compared with their respective glucose concentrations, which are represented by the line from 0 . Ach, $10 \mu \mathrm{M}$ of acetylcholine in presence of $10 \mu \mathrm{M}$ of neostigmine $+8.3 \mathrm{mM}$ of glucose; Epi, $1 \mu \mathrm{M}$ epinephrine $+16.7 \mathrm{mM}$ of glucose. ${ }^{\Omega} P<0.001$ compared with $8.3 \mathrm{mM}$ of glucose; ${ }^{\#} P<0.001$ compared with $16.7 \mathrm{mM}$ of glucose; ${ }^{*} P<0.05$ and ${ }^{* *} P<0.001$ compared with the respective control group.

the islets were incubated with basal concentration of glucose and AGEs, the insulin release was increased. On the other hand, islets incubated with higher glucose concentrations and AGEs exhibited a great inhibition of the insulin release. These data indicate a possible interaction of AGE in a dual manner on the regulation of glucose-stimulated insulin secretion (GSIS). This AGE regulation could be related to the metabolic state of the cell. A previous study has shown that MG exerts a major damaging effect on INS-1E cells impairing both insulin action and secretion, which includes impairment of the insulin-induced phosphorylation of the insulin receptor (IRS) and activation of the glycogen synthase kinase 3 (GSK3) with its reduced phosphorylation response to insulin [19].

To further investigate the AGE action on insulin secretion, we investigated the involvement of ATP-regulated potassium channels $\left(\mathrm{K}_{\mathrm{ATP}}^{+}\right)$. The blocking of the $\mathrm{K}_{\mathrm{ATP}}^{+}$by high extracellular potassium concentration led to increased insulin secretion even in low levels of glucose, as seen in the literature and in our results. Furthermore, the addition of AGEs induced even higher secretion in combination with extracellular potassium. An amplifying pathway augments insulin secretion without a reduced $\mathrm{K}_{\text {ATP }}^{+}$permeability $\left(\mathrm{K}_{\mathrm{ATP}}^{+}\right.$ independent pathway), indicating that glucose controls the insulin secretion by other additional pathways $[9,20,21]$. This suggests that AGEs recruit the $\mathrm{K}_{\mathrm{ATP}}^{+}$independent pathway. 


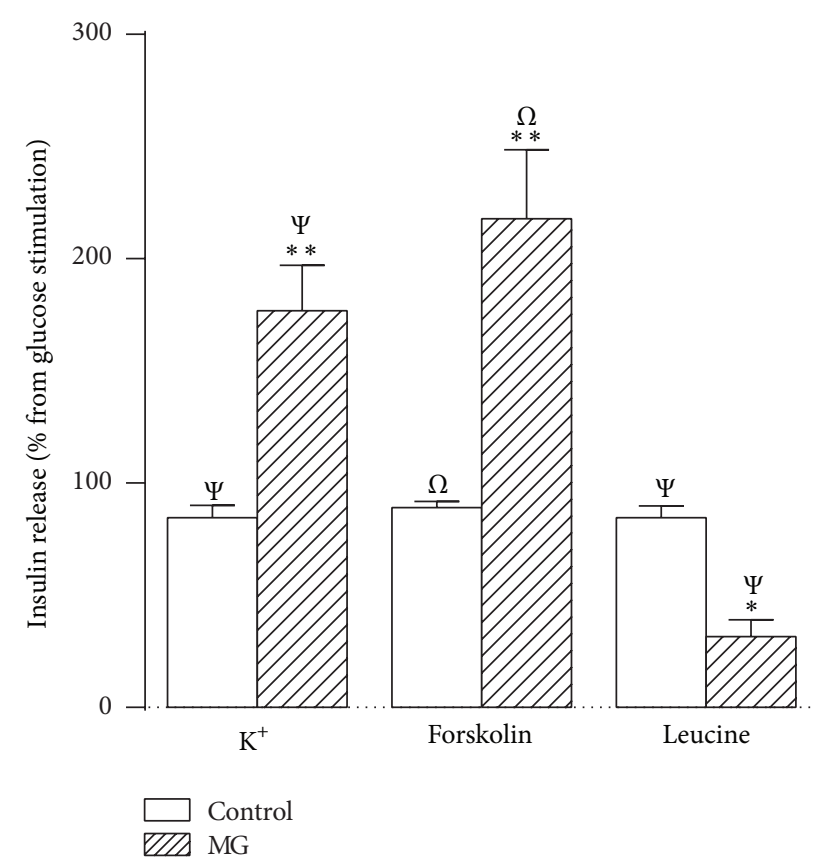

FIGURE 3: Effect of $\mathrm{K}^{+}$, forskolin, or leucine on GSIS. Insulin secretion was stimulated or inhibited by $\mathrm{K}^{+}$, forskolin, or leucine, as indicated below the $x$-axis, in absence or presence of methylglyoxal. Bars represent the mean \pm S.E.M. of the percentage of insulin release compared with their respective glucose concentrations, which are represented by the line from $0 . \mathrm{K}^{+}, 40 \mathrm{mM}$ of potassium $+5.6 \mathrm{mM}$ of glucose; forskolin, $10 \mu \mathrm{M}$ of forskolin $+8.3 \mathrm{mM}$ of glucose; leucine, $10 \mathrm{mM}$ of leucine $+5.6 \mathrm{mM}$ of glucose. ${ }^{\Psi} P<0.001$ compared with $5.6 \mathrm{mM}$ of glucose; ${ }^{\Omega} \mathrm{P}<0.001$ compared with $8.3 \mathrm{mM}$ of glucose; ${ }^{\#} P<0.001$ compared with $16.7 \mathrm{mM}$ of glucose; ${ }^{*} P<0.05$ and ${ }^{* *} P<0.001$ compared with the respective control group.

Acetylcholine is one potent modulator of GSIS through its action on cholinergic muscarinic receptors present throughout the insulin secreting cells. When incubated with glucose and acetylcholine, the insulin release was highly increased. Otherwise, when these cells received also the AGE compound, they exhibited a rough decrease in insulin secretion, even lower than the secretion exhibited by islets only in presence of glucose. In agreement with previous studies, it seems that AGEs activate pathways of beta-cell damage, through generation of mitochondrial superoxide, which can lead to an impairment of insulin secretion [17, 22]. The cholinergic muscarinic receptors are classified as $G$ protein coupled receptors (GPCR) and are regulated by phosphorylation following acetylcholine stimulation. These receptors couple with various downstream pathways such as the increase or decrease in cyclic AMP (cAMP) levels and stimulation of phospholipase C (PLC) with the formation of IP3 [23, 24]. In the same line, the adrenergic receptors are also formed of GPCR, but are targets of the catecholamines, and islets incubated with epinephrine presented a great inhibition of GSIS. On the other hand, the addition of AGEs caused a slight decrease in the epinephrine-induced inhibition of insulin release. To further explore the involvement of AGEs and cAMP levels, we activated the adenyl cyclase (AC) with forskolin [25], which resulted in increased insulin secretion when islets were incubated with only $8.3 \mathrm{mM}$ of glucose. Adding the AGEs to this AC-activated pathway assay resulted in around 2-fold more insulin release. It is evident that AGEs may have a cross-talk interaction with the AC downstream pathway. Whether the AGEs are acting or not in those downstream pathways remains to be further studied.

We further analyzed the insulin secretion stimulated by leucine and MG. Leucine is known to stimulate insulin release in normal beta-cells by two mechanisms. Firstly, by degradation through transamination pathway producing $\alpha$ ketoisocaproate, a metabolite which is a potent secretagogue allowing stimulation of insulin secretion through subsequent mitochondrial oxidation. Secondly, by the allosteric activation of glutamate dehydrogenase resulting in increased glutaminolysis, which also stimulates mitochondrial oxidation. Both mechanisms lead to an increase of the metabolic flux rate through the citric acid cycle, which increases the ATP production [26-28]. Our findings show that insulin release was increased in a basal concentration of glucose in presence of leucine; however, in the presence of AGEs this leucine-increased insulin secretion is blocked and is similar to the secretion levels from the control situation $(5.6 \mathrm{mM}$ of glucose). This latter result provides an insight that AGEs may be acting directly in the mitochondria, which is in agreement with a previous study supporting the idea that AGEs impair the secretion of pancreatic beta-cells at least in part through oxidative stress mechanisms [29]. Impaired mitochondrial function is also reported both in vivo and in vitro as a cause of insulin secretory dysfunction resulting from AGEs treatment $[14,15]$. Another study has pointed out that the effects of AGEs, in a low concentration for longer exposure period, are mainly caused through a reduction in the expression of the malate dehydrogenase $(M d h 1 / 2)$ gene, which plays an important role within the mitochondria [30]. Beyond the oxidative stress, AGEs are also formed in presence of hyperglycemia, but they still can be obtained from the diet $[6-8,31]$. AGEs bind to their receptors for AGE (RAGE) resulting in a downstream signaling activation, generation of intracellular oxygen free radicals, and the activation of gene expression $[22,32]$ that could be involved in the inhibition of leucine-potentiated insulin release.

\section{Conclusions}

Altogether, we provide several evidences that AGEs might regulate the insulin secretion through specific and different pathways within the pancreatic islets, which remain to be revealed. Recent findings together with our data bring up the idea that AGEs can effectively inhibit or stimulate insulin secretion pathways. In addition to their chronically deleterious long-term effects in beta-cells, the AGEs acute effects described in the present work may participate in the onset of diabetes.

\section{Conflict of Interests}

The authors declare that there is no conflict of interests regarding the publication of this paper. 


\section{Authors' Contribution}

Ghada Elmhiri and Luiz Felipe Barella both have contributed equally to the paper.

\section{Acknowledgment}

This work was funded by the Institut Polytechnique LaSalle Beauvais.

\section{References}

[1] G. Danaei, M. M. Finucane, Y. Lu et al., "National, regional, and global trends in fasting plasma glucose and diabetes prevalence since 1980: systematic analysis of health examination surveys and epidemiological studies with 370 country-years and $2 \cdot 7$ million participants," The Lancet, vol. 378, no. 9785, pp. 31-40, 2011.

[2] M. Brownlee, "Biochemistry and molecular cell biology of diabetic complications," Nature, vol. 414, no. 6865, pp. 813-820, 2001.

[3] P. S. Sharp, S. Rainbow, and S. Mukherjee, "Serum levels of low molecular weight advanced glycation end products in diabetic subjects," Diabetic Medicine, vol. 20, no. 7, pp. 575-579, 2003.

[4] K. J. Wells-Knecht, D. V. Zyzak, J. E. Litchfield, S. R. Thorpe, and J. W. Baynes, "Mechanism of autoxidative glycosylation: identification of glyoxal and arabinose as intermediates in the autoxidative modification of proteins by glucose," Biochemistry, vol. 34, no. 11, pp. 3702-3709, 1995.

[5] P. J. Thornalley, "The glyoxalase system: new developments towards functional characterization of a metabolic pathway fundamental to biological life," Biochemical Journal, vol. 269, no. 1, pp. 1-11, 1990.

[6] A. Lapolla, D. Fedele, and P. Traldi, "Glyco-oxidation in diabetes and related diseases," Clinica Chimica Acta, vol. 357, no. 2, pp. 236-250, 2005.

[7] H. Vlassara, "Advanced glycation in health and disease: role of the modern environment," Annals of the New York Academy of Sciences, vol. 1043, pp. 452-460, 2005.

[8] T. Goldberg, W. Cai, M. Peppa et al., "Advanced glycoxidation end products in commonly consumed foods," Journal of the American Dietetic Association, vol. 104, no. 8, pp. 1287-1291, 2004.

[9] J.-C. Henquin, "Triggering and amplifying pathways of regulation of insulin secretion by glucose," Diabetes, vol. 49, no. 11, pp. 1751-1760, 2000.

[10] P. Gilon and J.-C. Henquin, "Mechanisms and physiological significance of the cholinergic control of pancreatic $\beta$-cell function," Endocrine Reviews, vol. 22, no. 5, pp. 565-604, 2001.

[11] J. C. Henquin, "Regulation of insulin secretion: a matter of phase control and amplitude modulation," Diabetologia, vol. 52, no. 5, pp. 739-751, 2009.

[12] M. S. Winzell and B. Ahrén, "G-protein-coupled receptors and islet function-implications for treatment of type 2 diabetes," Pharmacology \& Therapeutics, vol. 116, no. 3, pp. 437-448, 2007.

[13] Y. Zhu, T. Shu, Y. Lin et al., "Inhibition of the receptor for advanced glycation endproducts (RAGE) protects pancreatic $\beta$ cells," Biochemical and Biophysical Research Communications, vol. 404, no. 1, pp. 159-165, 2011.

[14] Z. Zhao, C. Zhao, H. Z. Xu et al., "Advanced glycation end products inhibit glucose-stimulated insulin secretion through nitric oxide-dependent inhibition of cytochrome c oxidase and adenosine triphosphate synthesis," Endocrinology, vol. 150, no. 6, pp. 2569-2576, 2009.

[15] M. T. Coughlan, F. Y. Yap, D. C. Tong et al., "Advanced glycation end products are direct modulators of $\beta$-cell function," Diabetes, vol. 60, no. 10, pp. 2523-2532, 2011.

[16] C. Gravena, P. C. Mathias, and S. J. H. Ashcroft, "Acute effects of fatty acids on insulin secretion from rat and human islets of Langerhans," Journal of Endocrinology, vol. 173, no. 1, pp. 73-80, 2002.

[17] F. Costal, E. Oliveira, A. Raposo et al., "Dual effect of advanced glycation end products in pancreatic islet apoptosis," Diabetes/Metabolism Research and Reviews, vol. 29, no. 4, pp. 296307, 2013.

[18] J. C. de Oliveira, P. C. Lisboa, E. G. de Moura et al., "Poor pubertal protein nutrition disturbs glucose-induced insulin secretion process in pancreatic islets and programs rats in adulthood to increase fat accumulation," Journal of Endocrinology, vol. 216, no. 2, pp. 195-206, 2013.

[19] F. Fiory, A. Lombardi, C. Miele, J. Giudicelli, F. Beguinot, and E. Van Obberghen, "Methylglyoxal impairs insulin signalling and insulin action on glucose-induced insulin secretion in the pancreatic beta cell line INS-1E," Diabetologia, vol. 54, no. 11, pp. 2941-2952, 2011.

[20] L. Best, A. P. Yates, and S. Tomlinson, "Stimulation of insulin secretion by glucose in the absence of diminished potassium $(86 \mathrm{Rb}+)$ permeability," Biochemical Pharmacology, vol. 43, no. 11 , pp. 2483-2485, 1992.

[21] Y. Sato and J.-C. Henquin, “The K+-ATP channel-independent pathway of regulation of insulin secretion by glucose: in search of the underlying mechanism," Diabetes, vol. 47, no. 11, pp. 1713$1721,1998$.

[22] A. Bierhaus, M. A. Hofmann, R. Ziegler, and P. P. Nawroth, "AGEs and their interaction with AGE-receptors in vascular disease and diabetes mellitus. I. The AGE concept," Cardiovascular Research, vol. 37, no. 3, pp. 586-600, 1998.

[23] S. R. M. Madiraju and V. Poitout, "G protein-coupled receptors and insulin secretion: 119 and counting," Endocrinology, vol. 148, no. 6, pp. 2598-2600, 2007.

[24] B. Ahrén, "Islet G protein-coupled receptors as potential targets for treatment of type 2 diabetes," Nature Reviews Drug Discovery, vol. 8, no. 5, pp. 369-385, 2009.

[25] R. A. Ribeiro, S. L. Balbo, L. P. Roma et al., "Impaired muscarinic type 3 (M3) receptor/PKC and PKA pathways in islets from MSG-obese rats," Molecular Biology Reports, vol. 40, no. 7, pp. 4521-4528, 2013.

[26] C. Li, H. Najafi, Y. Daikhin et al., "Regulation of leucinestimulated insulin secretion and glutamine metabolism in isolated rat islets," Journal of Biological Chemistry, vol. 278, no. 5, pp. 2853-2858, 2003.

[27] Z. Gao, R. A. Young, G. Li et al., "Distinguishing features of leucine and $\alpha$-ketoisocaproate sensing in pancreatic $\beta$-cells," Endocrinology, vol. 144, no. 5, pp. 1949-1957, 2003.

[28] A. Sener and W. J. Malaisse, "L-leucine and a nonmetabolized analogue activate pancreatic islet glutamate dehydrogenase," Nature, vol. 288, no. 5787, pp. 187-189, 1980.

[29] N. Lin, H. Zhang, and Q. Su, "Advanced glycation end-products induce injury to pancreatic beta cells through oxidative stress," Diabetes and Metabolism, vol. 38, no. 3, pp. 250-257, 2012.

[30] H. Hachiya, Y. Miura, K. Inoue, K. H. Park, M. Takeuchi, and K. Kubota, "Advanced glycation end products impair glucoseinduced insulin secretion from rat pancreatic $\beta$-cells," Journal 
of Hepato-Biliary-Pancreatic Sciences, vol. 21, no. 2, pp. 134-141, 2014.

[31] B. H. R. Wolffenbuttel, D. Giordano, H. W. Founds, and R. Bucala, "Long-term assessment of glucose control by haemoglobin-AGE measurement," The Lancet, vol. 347, no. 9000, pp. 513-515, 1996.

[32] S. D. Yan, D. Stern, and A. M. Schmidt, "What's the RAGE? The receptor for advanced glycation end products (RAGE) and the dark side of glucose," European Journal of Clinical Investigation, vol. 27, no. 3, pp. 179-181, 1997. 


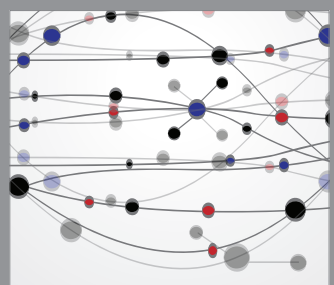

The Scientific World Journal
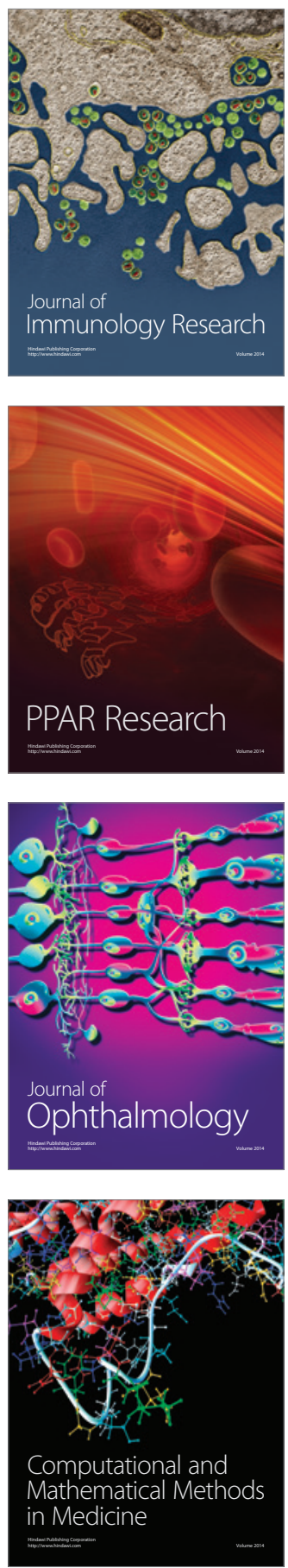

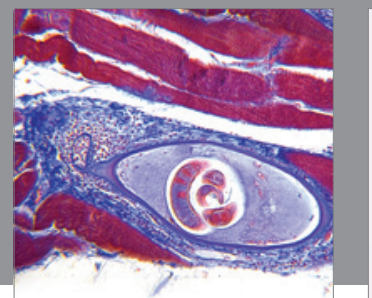

Gastroenterology

Research and Practice
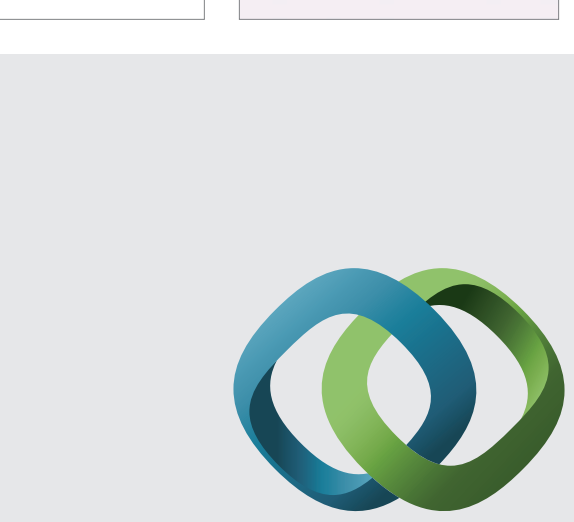

\section{Hindawi}

Submit your manuscripts at

http://www.hindawi.com

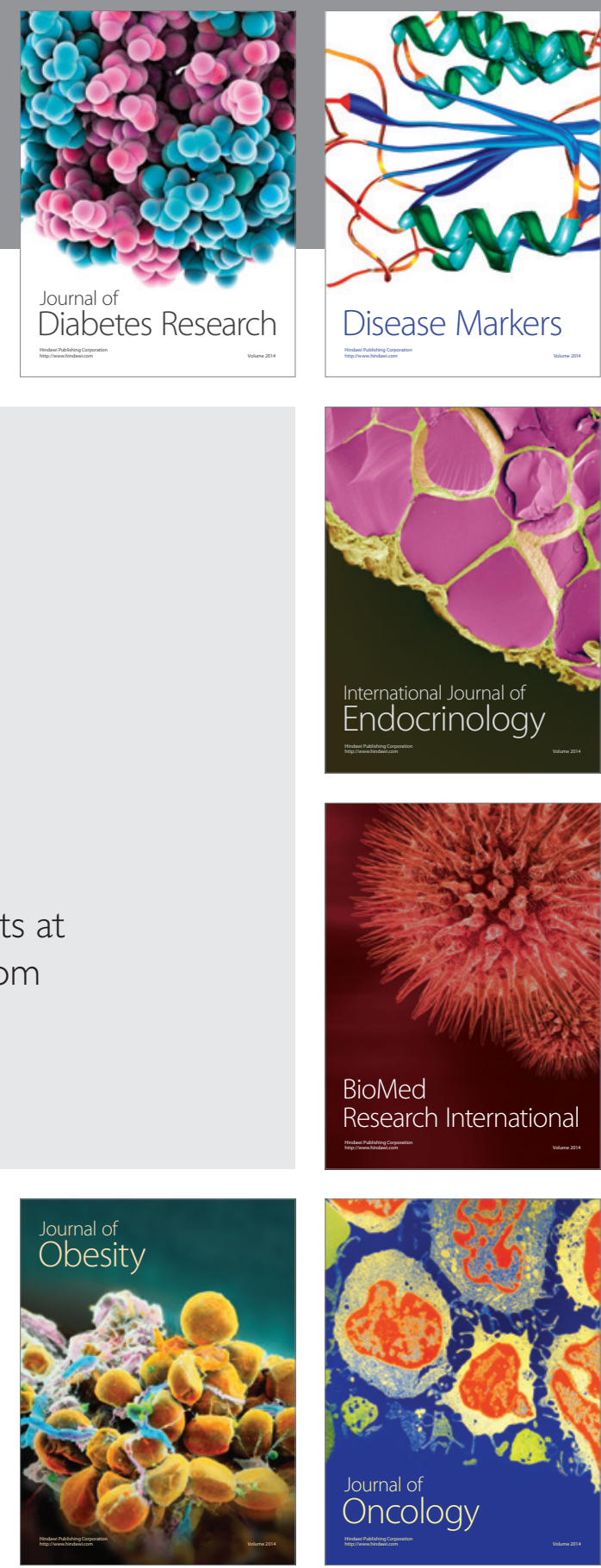

Disease Markers
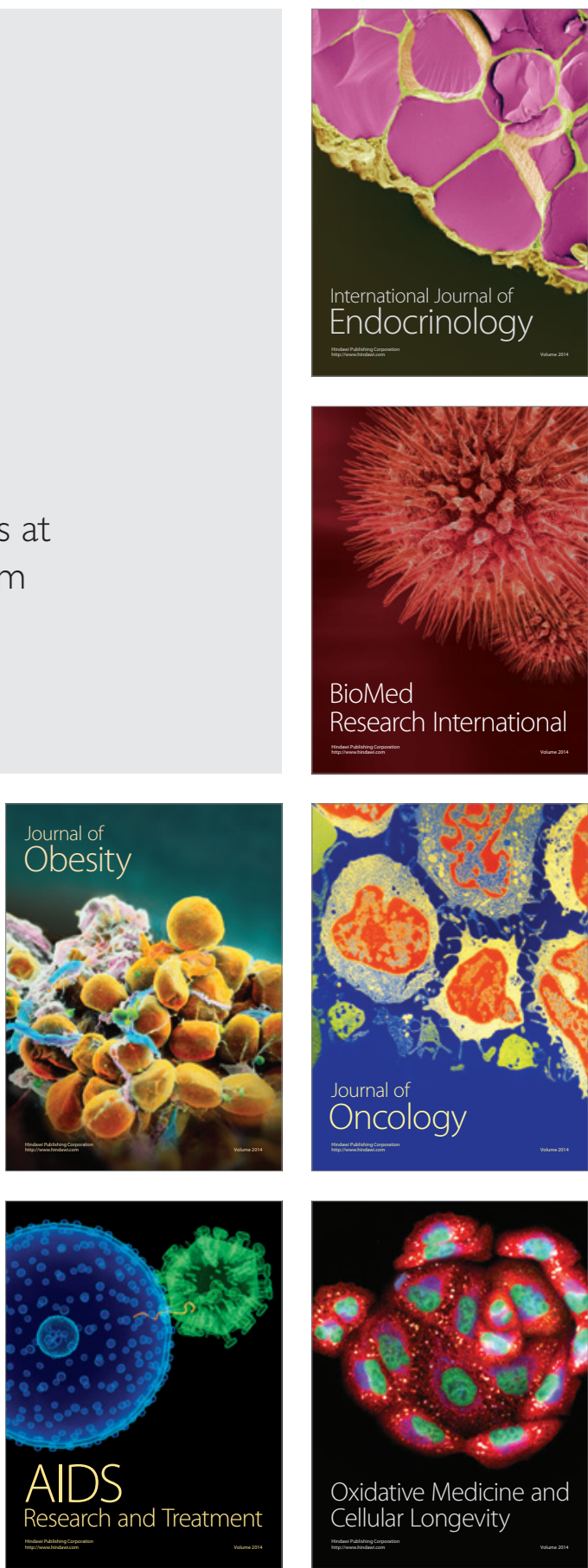